\title{
Generalized Subcutaneous Emphysema Caused by Injection of Air into the Penis for Autoerotic Purposes
}

\author{
Y. Ural N. Muthen U. Engelmann S. Wille \\ Department of Urology, University of Cologne, Cologne, Germany
}

\section{Key Words}

Autoerotic purposes $\cdot$ Subcutaneous emphysema $\cdot$ Sadomasochism

\begin{abstract}
The injection of air or water into the scrotum has been described only a few times so far in the literature. Injection of air into the penis and its consequences has not been described at all. Here, we present the case of a young man who, acting on his previously suppressed sexual fantasies, injected air into his penis and caused generalized subcutaneous emphysema.

(c) 2013 S. Karger AG, Basel
\end{abstract}

\section{Introduction}

Nowadays, we are confronted more and more with the obscure and extraordinary sexual fantasies of human beings, especially in the medical field - and even more often in the urological department. Therefore, we, as academics, have to be aware of the different variety of human sexual deviation and its medical consequences. In addition, we have to try to prevent the worst medical outcomes by providing information to both our colleagues and patients.

\section{Case Report}

A 31-year-old man came to our emergency room seeking medical attention for severe neck pain. He informed us that 2 days before, after excessive consumption of alcohol, he had 
made an incision into the skin of his penis below the frenulum by means of a needle in order to insufflate air into the opening with a standard ball pump (fig. 1) for autoerotic purposes. He had been suffering from severe pain in the neck area since the morning.

Below the frenulum, a reddened incision of approximately $5 \mathrm{~mm}$ in diameter could be seen which extended into the hypodermis. Apart from that, the penis was without pathological symptoms such as swelling, hyperthermia or redness. Also, the penis was not rigid and there were no crepitations. In the neck area and on the remaining trunk, crepitations could be felt. This was where the patient's pain was located, radiating dorsolaterally from the cervical area into the trapezius muscle.

The psychological exploration of the patient's sexuality clarified that he had distinctive sadomasochistic masturbation fantasies. The patient had not pursued these sadomasochistic thoughts so far because he had not been aware of them.

The laboratory results were unremarkable. Because the patient was capable of spontaneous and pain-free micturition and the external examination showed no anomalies, a cystoscopic examination of the urethra was not carried out. A CT examination of the abdomen revealed generalized subcutaneous emphysema extending from the scrotum to the abdomen and the cervix (fig. 2).

\section{Therapy and Development}

The patient was admitted for observation. He received antibiotic treatment with a gyrase inhibitor in order to avoid an infection of the area around the frenulum. The medical focus was on the neck pain caused by the air gradually travelling through the hypodermis from the genital area to the cranial area. The pain was stabilized without difficulty by means of metamizole. After 2 days, it was no longer possible to detect any crepitations in the neck area.

\section{Discussion}

A 31-year-old male patient used a standard air pump in order to insufflate air under the skin of the penis for autoerotic purposes. Insufflation caused only a limited arousal, but generalized skin emphysema. Generalized skin emphysema can be caused by a variety of reasons such as a spontaneous or traumatic pneumothorax, an infection with aerogenous bacteria or artificial formation, as in this case.

Pneumoscrotum is a rare symptom, usually following blunt trauma of the thorax. The air spreads from the destroyed alveoli via the mediastinum downwards along the fasciae, the perirenal area and the retroperitoneum to the inguinal canal and the scrotum [1,2]. Other causes of pneumoscrotum can be endoscopic operations, visceral perforation, emphysematous pyelonephritis or, as in the case treated here, artificial trauma followed by inflation of air for autoerotic purposes [3-5].

Only 2 cases of artificially caused generalized skin emphysema are described in the medical literature. The first is a 1952 report of a 27 -year-old music student who pumped air into his scrotum 'in sexual disorientation in order to find perverted sexual satisfaction'. In that case, the air also travelled upwards to the neck, causing a feeling of pressure in the laryngeal area which worried the patient and led him to seek medical attention. The second case is a 1959 report of a psychotic patient who insufflated the scrotum through an incision with a copper tube with suicidal intent, which also led to generalized skin emphysema $[6,7]$.

However, generalized skin emphysema is a symptom that must not be underestimated. For example, the potentially lethal complication of an air embolism must be watched out for. 
Also, bacteria entering the penis and scrotum through injuries can cause serious infections such as necrotizing fasciitis.

Human sexual fantasy has no limits, which is why in the field of urology we must always expect extraordinary injuries and - like in this case - sexual deviation, in terms of sadomasochism, as the cause of the injuries. Obviously, this insufflation was a demarcation of a sadomasochistic fantasy which the patient had not been aware of, and which could have led to severe complications. In this case, the emphysema disappeared after a few days without any therapeutic measures.

From the urological point of view, doctors' attention should not be limited to the treatment of the somatic symptom. Furthermore, patients with such sexual deviation should be offered appropriate support in order to be able to live out their fantasies without causing harm to themselves.

\section{References}

1 Su JT, Hsia JY, Hu SY, Tsan YT, Lin TC, Wang LM: Pneumoscrotum after blunt chest trauma. Urology 2011;77:75-76.

-2 Wakabayashi Y, Bush WH Jr: Pneumoscrotum after blunt chest trauma. J Emerg Med 1994;12:603-605.

3 Brandt LJ: Subcutaneous emphysema of penis and scrotum mimicking gas gangrene: a rare complication of ERCP. Gastrointest Endosc 2011;73:613-615.

-4 Huang HL, Chang CC, Chen CC, Huang TK: Subcutaneous and scrotal emphysema following suprapubic cystostomy in a patient with colovesical fistula. J Chin Med Assoc 2010;73:265-267.

5 Modi P, Goel R, Dodia S: Scrotal extension of emphysematous pyelonephritis. Int Urol Nephrol 2007;39:405407.

6 Lazar I: General artificial emphysema as a sequel to an attempted suicide (in German). Dtsch Z Gesamte Gerichtl Med 1959;49:106-108.

7 Schumann E: Artificial emphysema of the scrotum with subcutaneous spreading over the trunk (in German). Zentralbl Chir 1952;77:543-545.

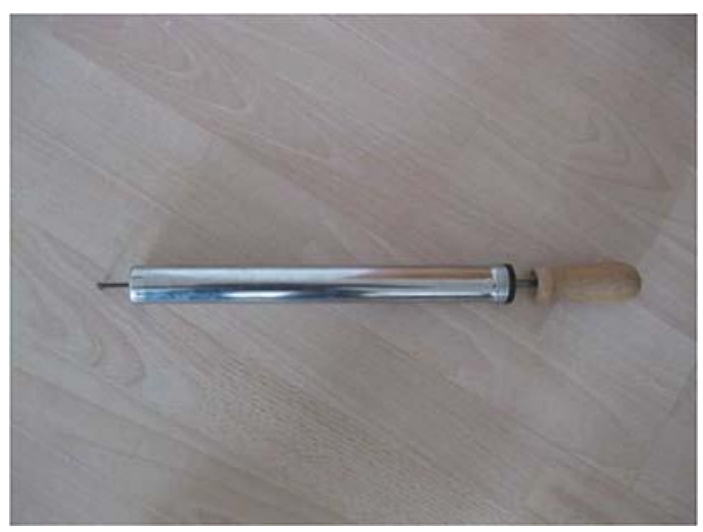

Fig. 1. A standard air pump. 
Case Reports in

Nephrology and

Urology
Case Rep Nephrol Urol 2013;3:117-120

DOI: $10.1159 / 000355514$

Ural et al: Generalized Subcutaneous Emphysema Caused by Injection of Air into the Penis for Autoerotic Purposes

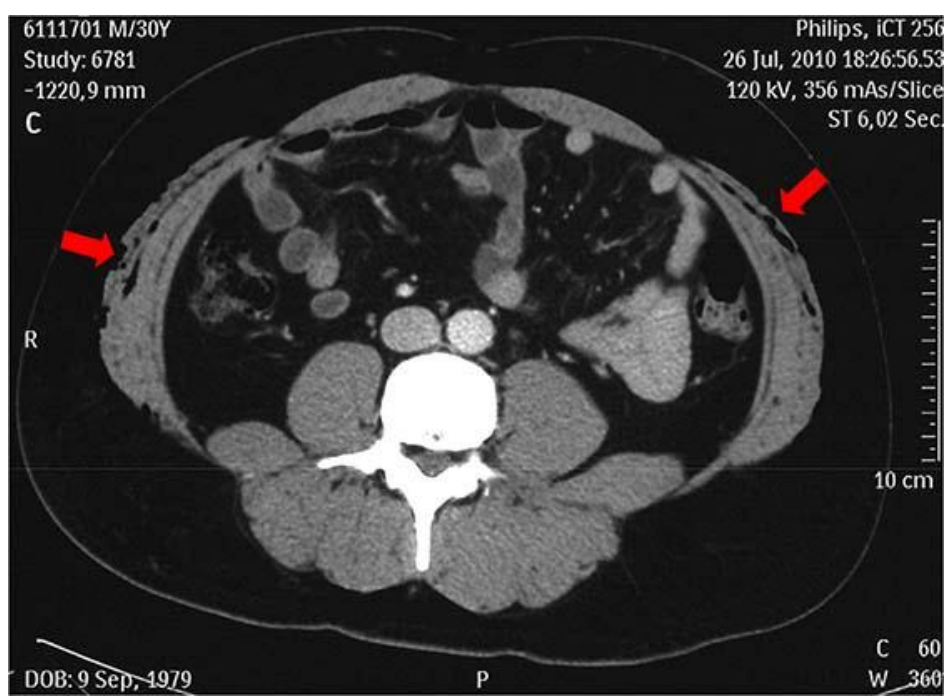

Fig. 2. Computed tomography of the abdomen and pelvis showing subcutaneous air pockets on both sides (arrows). 